\title{
CAUSES OF UPPER GI BLEED: VARICEAL OR NON-VARICEAL.
}

\footnotetext{
1. MBBS, FCPS (Med)

Assistant Professor Medicine

Mayo Hospital, King Edward Medical

University, Lahore.*

2. MBBS, FCPS (Med)

Assistant Professor Emergency Medicine*

3. MBBS, FCPS (Med)

Assistant Professor Medicine

The University of Faislabad.

4. MBBS, FCPS (Med)

Associate Professor Medicine

The University of Faislabad.

5. MBBS, FCPS (Med)

Senior Registrar Medicine*

6. MBBS, FCPS (Pead)

Assistant Professor Pediatric Medicine

Shifa Tameer-e-Millat University,

Islamabad.

7. MBBS, PGPN (Boston)

Medical Officer

Govt General Hospital, Faisalabad.
}

Correspondence Address:

Dr. Talha Munir

Medicine

Mayo Hospital, King Edward Medica

University, Lahore.

ahsanjahangir194@gmail.com

Article received on:

09/07/2019

Accepted for publication:

25/10/2019
Talha Munir ${ }^{1}$, Muhammad Naeem Safdar ${ }^{2}$, Salman Azhar ${ }^{3}$, Rizwan Rasool Khan ${ }^{4}$, Samara Siddique $^{5}$, Sahira Aaraj', Muhammad Ahsan ${ }^{7}$

ABSTRACT... Objectives: To determine the frequency of esophageal variceal bleed in patients with upper Gl bleed presenting in a tertiary care hospital. Study Design: Cross sectional survey. Setting: Department of Medicine, Mayo Hospital, Lahore and Madinah Teaching Hospital, Faisalabad. Period: 6 months from 01-06-2018 to 31-12-2018. Material \& Methods: Two hundred patients with upper Gl bleed were included in the study. All the patients had upper Gl endoscopy to determine the esophageal variceal bleeding which was documented as frequency distribution table. Results: Esophageal variceal bleed was seen among 108 (54\%) patients while it was not present among 92 (46\%) patients. Conclusion: Esophageal variceal bleeding is frequently present among patients with upper GI bleeding and should be suspected in every patient with upper Gl bleeding.

Key words: $\quad$ Esophageal Variceal Bleeding, Upper Gastrointestinal Bleeding, Upper Gl Endoscopy.

Article Citation: Munir T, Safdar MN, Azhar S, Khan RR, Siddique S, Aaraj S, Ahsan M. Causes of Upper Gl Bleed: Variceal or non-variceal. Professional Med $J$ 2020; 27(4):820-824. DOI: 10.29309/TPMJ/2020.27.04.3920

\section{INTRODUCTION}

Patients presenting with bleeding from any point proximal to the anatomical landmark i.e. ligament of Treitz is labeled as upper gastrointestinal bleeding although some also include the proximal jejunum. ${ }^{1}$ Among the most common causes of upper Gl bleeding are peptic ulcer disease (35 $62 \%)$, gastro esophageal varices $(4-31 \%)$ due to chronic liver disease, Mallory Weis tear (4 - 13\%), gastro duodenal ulcers or erosions, esophagitis (2-8\%), gastric neoplasm ( $1-4 \%)$ and others as angiodysplasia, Dieulafoy's lesions, aortoentric fistula, hemobilia, hereditary hemorrhagic telangiectasia, uremia and coagulation disorders. ${ }^{2}$

Most of the cases ofUGIB like gastritis, esophagitis, Cameron erosions, varices and ulcers can lead to anemia due to iron deficiency, but almost none of them present with simple pallor or anemia in the emergency department. These patients come to emergency with complaints like bleeding through vomiting (hematemesis - mostly massive bleeding), black stools (melena), fresh bleeding through stools (hematochezia) and/or with shock and hypothension. ${ }^{3-5}$

The incidence of UGIB along with their causes varies from populations to populations, with an estimated prevalence of about 100 cases in a population of one lakh per year. ${ }^{6} \mathrm{UGIB}$ is four times more common when compared to the incidence of lower Gl bleed. Morbidity and mortality is also more for UGIB patients. According to an estimate the mortality from UGIB has reached to $10 \%$ in the developing countries. ${ }^{6}$

Diagnosis and management of non-variceal UGIB has revolutionized since the last 5 years. Endoscopic techniques with medical therapy till the surgical therapy as last resort after the failure of medical therapy. ${ }^{7}$

Esophageal varices are the dilated tortuous veins due to increased pressure in the esophageal plexus due to development of portal hypertension after impairment in the portal venous flow inside the hepatic system with the development of chronic liver disease and liver cirrhosis. The 
flow of blood is diverted to the esophageal sub epithelial and submucosal veins through coronary stomach veins. ${ }^{8}$ A retrospective study conducted in England showed that in hospital mortality of patients with cirrhosis and variceal bleed decreased from $43 \%$ in 1980 to $15 \%$ in 2000 in concurrence with an early and combined use of pharmacological, endoscopic therapy and short term antibiotic prophylaxis. ${ }^{9}$

Gastroesophageal varices occur in 30\% cases of compensated chronic liver disease (CLD) and more than $50 \%$ of decompensated CLD cases. ${ }^{10}$ Esophageal variceal bleed (EVB) occurs in average $15 \%$ patients of CLD in a year and it is a medical emergency with significant morbidity and mortality. ${ }^{11}$ Advanced techniques with medication improve about $2 / 3^{\text {rd }}$ episodes of variceal bleed. ${ }^{12}$

Chronic liver disease is more common in our part of world due to high prevalence of liver cirrhosis. In one study, out of 892 patients, esophageal varices were seen in 580 (65\%) cases and gastric erosions in 133 (14.96\%) cases $^{13}$, 44\% was reported by another study with PUD ${ }^{14}$ and $22.75 \%$ in a local setting of Pakistan. ${ }^{15}$ The aim of this study was that there was marked variability in data regarding frequency of esophageal variceal bleed in patients presenting with UGIB in local studies, so reassessment is required time to time.

\section{MATERIAL AND METHODS}

This cross sectional survey was conducted in the Medical Unit-III of Mayo hospital, Lahore and Medicine Department of Madinah Teaching Hospital, Faisalabad six months after approval from the respective hospital's ethical review committees. Patients of both genders aging between 15 to 70 years having history of UGIB (hematemesis or melena or both) for less than 48 hours confirmed by endoscopy were included in the survey. Esophageal varices were considered as dilated collaterals in the lower esophagus that interconnect portal and systemic circulation in patients with portal hypertension.

Endoscopically, esophageal varices were defined as irregular, serpiginous, bluish structures running longitudinally in the submucosa of esophageal wall. Bleeding from upper part of the gastrointestinal tract i.e. from esophagus down to the first part of duodenum, which was manifested by hematemesis, melena or both, is defined as upper gastrointestinal bleeding on basis of upper Gl endoscopy. Patients with history of bleeding in the upper or lower respiratory tract assessed by history of epistaxis or blood in sputum, patients not fit for endoscopy due to cardiac disease like recent myocardial infarction and heart failure assessed by history, physical examination, ECG and Chest X-ray including those who had drug history of beta blockers or nitrates and patients who had systolic B.P $<90 \mathrm{mmHg}$ and diastolic B.P $<60 \mathrm{mmHg}$.

200 patients (meeting the inclusion/exclusion criterion) were enrolled from Medical Unit III, Mayo Hospital Lahore and Medicine Department of Madinah Teaching Hospital, Faisalabad after informed consent. Demographics like name, age, gender and address were noted. Endoscopic examination of upper Gl tract was carried out in central endoscopy unit of Mayo Hospital Lahore and Medicine Department of Madinah Teaching Hospital, Faisalabad by a single gastroenterologist who had experience of at least five years. Those patients who had esophageal varices (yes/ no) meeting the operational definition criterion was noted on proforma.

Data was entered and analyzed by Statistical Package for Social Science (SPSS) version 11. Mean \pm S.D was calculated for quantitative variables like age while qualitative variables like gender and presence of esophageal variceal bleed were calculated for frequencies/ percentages. Stratification was done for age and gender to control the effect modifiers.

\section{RESULTS}

Two hundred patients with diagnosis of upper GI bleeding were included in the study. The mean age of the patients was $41.34+17.01$ years. The age range was from 15 years to 70 years. (Table-l) 


\begin{tabular}{|l|c|c|}
\hline \multicolumn{1}{|c|}{ Age in Years } & No. of Patients & Percentage \\
\hline $15-20$ & 2 & 0.5 \\
\hline $21-30$ & 29 & 14.5 \\
\hline $31-40$ & 67 & 33.5 \\
\hline $41-50$ & 73 & 37.5 \\
\hline $51-60$ & 19 & 9.5 \\
\hline $61-70$ & 10 \\
\hline Mean + SD & \multicolumn{2}{|c|}{$41.34+17.01$} \\
\hline Range & \multicolumn{2}{|c|}{$13-70$} \\
\hline \multicolumn{2}{|c|}{ Table-I. Distribution by age $(\mathbf{n = 2 0 0})$} \\
\hline
\end{tabular}

Of the 200 patients included in the study, there were $122(61 \%)$ male patients and 78 (39\%) female patients in the study. The female to male ratio in the study was 1:1.56.

Out of the 200 patients, included in the study, esophageal variceal bleed was seen among 108 (54\%) patients while it was not present among 92 (46\%) patients. (Table-II)

\begin{tabular}{|c|c|c|}
\hline $\begin{array}{l}\text { Esophageal Varices } \\
\text { in Patients of UGIB }\end{array}$ & Number & Frequency \\
\hline Yes & 108 & $54 \%$ \\
\hline No & 92 & $46 \%$ \\
\hline Total & 200 & $100 \%$ \\
\hline
\end{tabular}

\section{DISCUSSION}

Esophageal variceal bleed is a life threatening condition and can present as upper gastrointestinal bleeding. This study was carried out in an effort to detect that how common was the esophageal varices among patients with upper gastrointestinal bleeding. This is one of the largest series including 200 patients. The results of this study showed a high frequency of esophageal variceal bleed among the patients with UGIB.

In literature, the authors have described various frequencies of the esophageal variceal bleed among the patients with UGIB. The mean age of the patients in our study was $41.34+17.01$ years. This was almost similar to that of study by Atif $\mathrm{MA}^{16}$, i.e. $42.45 \pm 16.52$ years and Khan SA, et al. 61 i.e. $41.64 \pm 13.56$ years. However, Qari FA, et al. ${ }^{18}$ showed a higher mean age of the patients i.e. 51 years.

There were $61 \%$ male patients and $39 \%$ patients were female with a female to male ratio of 1:1.56. Similarly, in study by Khan SA, et al. ${ }^{17}$ male constituted $55.7 \%$ population and female $44.3 \%$. In study by Qari FA, et al. ${ }^{18}$ male patients dominated with a male to female ratio of 1.59:1.

Pasha MB, et al. ${ }^{19}$ carried a study among 100 patients with UGIB, in order to determine the frequency of various disorders. They found a high frequency of esophageal variceal bleed i.e. 53\%. Like our study, the majority of the patients had esophageal variceal bleed.

Bhutta S, et al. ${ }^{20}$ conducted a study on 958 patients with upper Gl bleeding. They detected a low incidence of esophageal varices as compared to ours i.e. $20 \%$ patients in their study had esophageal varices.

Najam un Nasir, et al. ${ }^{21}$ in a study from Mayo Hospital Lahore also found esophageal varices (54\%) to be the commonest cause of acute upper Gl bleed.

Atif $\mathrm{MA}$, et al. ${ }^{16}$ conducted a study based on endoscopic findings among 500 patients, 57\% were referred due to UGIB. Common endoscopic diagnoses were esophageal varices which were found among $44 \%$ patients.

Qari FA, et al. ${ }^{18}$ carried a retrospective study on a total of 3955 upper GI endoscopies performed during the study period for various indications. UGIB contributed to $1.76 \%$ of cases. Among their findings, esophageal varices was the most common finding detected among $57 \%$ cases of patients with upper Gl bleeding.

Khan SA, et al. ${ }^{17}$ documented their endoscopic findings among 88 patients who presented with upper Gl bleeding. They detected that most frequent cause of UGIB was esophageal varices which were present in $56.82 \%$ patients of their study. Again, like other authors they detected a 
high frequency of esophageal varices.

Duah $A$, et al reported that male to female ratio was $3.5: 1$ in his study on CLD patients with ChildPugh Classification $8.16 \%$ in class A, $43.54 \%$ in B, $48.3 \%$ class C and after endoscopy $90.60 \%$ had esophageal varices with $9.40 \%$ no varices: $82.22 \%$ large varices $17.8 \%$ had small varices. ${ }^{23}$

Hossain E, et $\mathrm{al}^{22}$ reported that upper GI endoscopy was done in all the UGIB patients and $45 \%$ patients were having medium sized, $27 \%$ had small sized and $19 \%$ had large sized varices.

Main cause of CLD with cirrhosis is viruses, proven on many studies. ${ }^{25-30}$ In the management of acute episodes, multidisciplinary approach which should include anesthetics, critical care, endoscopist and hepatologist lead to significant reduction in the morbidity and mortality. ${ }^{24}$

\section{CONCLUSION}

Esophageal variceal bleeding contributes a major bulk of patients with UGIB on upper GI endoscopy. So, it is recommended that every patient with UGIB should have upper GI endoscopy and should be suspected of having esophageal varices as a commonest cause of bleeding. This is also suggested that more studies should be carried on in this context in different setups.

\section{Copyright@ 25 Oct, 2019.}

\section{REFERENCES}

1. Chen ZJ, Freeman ML. Management of upper gastrointestinal bleeding emergencies: Evidencebased medicine and practical considerations. World J Emerg Med 2011; 2:5-12.

2. Mc Quaid KR. Alimentary Tract. In: Tierney LM, Mc Phee SJ, Papadakis MA. Current medical diagnosis and treatment. San Francisco: McGraw Hill 2011; 556-7.

3. Enestvedt BK, Gralnek IM, Mattek N, Lieberman DA, Eisen $G$. An evaluation of endoscopic indications and $\mathrm{fi}$ ndings related to nonvariceal upper-Gl hemorrhage in a large multicenter consortium. Gastrointest Endosc 2008; 67:422-9.

4. Van Leerdam ME. Epidemiology of acute upper gastrointestinal bleeding. Clin Gastroenterol 2008; 22:209-24.
5. Hallas J, Lauritsen J, Villadsen HD, Gram LF. Nonsteroidal anti-inflammatory drugs and upper gastrointestinal bleeding, identifying high-risk groups by excess risk estimates. Scand J Gastroenterol 1995; 30:438-44.

6. Fallah MA, Prakash C, Edmundowicz S. Acute gastrointestinal bleeding. Med Clin North Am 2000; 84:1183-1208.

7. Pongprasobchai S, Nimitvilai S, Chasawat J, Manatsathit S. Upper gastrointestinal bleeding etiology score for predicting variceal and non-variceal bleeding. World J Gastroenterol 2009; 15:1099-1104.

8. Cotran RS, Kumar V, Collins T, eds. Robbins pathologic basis of disease. $7^{\text {th }}$ ed. Philadelphia, Pa: WB Saunders Co 2004; 543-90.

9. Carbonell N, Pauwels A, Serfaty L, Fourdan O, Levy VG, Poupon R. Improved survival after variceal bleeding in patients with cirrhosis over past two decades. Hepatology 2004; 40:652-9.

10. D' Amico G, Pagliaro L, Bosch J. B e treatment of portal hypertension: A meta-analytic review. Hepatology 1995; 22:332-54.

11. North Italian Endoscopic Club (NIEC) for the study and treatment of esophageal varices. Prediction of the first variceal hemorrhage in patients with cirrhosis of the liver and esophageal varices. A prospective multicenter study. N Engl J Med 1988; 319:983-9.

12. Abid S, Jafri W, Hamid S, Salih M, Azam Z, Mumtaz K. Terlipressin vs. Octreotide in Bleeding Esophageal Varices as an Adjuvant Therapy With Endoscopic Band Ligation: A Randomized Double-Blind PlaceboControlled Trial. Am J Gastroenterol 2009; 104:617-3.

13. Chaudhary AW, Tabassum HM, Chaudhary MA. Pattern of upper gastrointestinal bleeding at Rahim Yar Khan. Ann King Edward Med Coll 2005; 11:282-3.

14. Adem T, Javed F, Khan S. Upper Gastrointestinal bleeding: An etiological study of 552 cases. J Pak Inst Med Sci 2004; 5:845-8.

15. Wasty W, Yousaf M, Mirza MR. Frequency of esophageal varices among patients undergoing GI endoscopy. Pak J Med Sci 2005; 21:164-7.

16. Atif MA, Ahmad I. Esophageal varices: Major endoscopic finding on upper GI endoscopy. Professional Med J 2008; 15:465-8.

17. Khan SA, Mustaf G, Khna TM, Taseer I. Frequency of various causes of upper gastrointestinal bleed (UGIB)at a Tertiary Care Hospital. 
18. Qari FA. Major causes of upper gastrointestinal bleeding at King Abdul Aziz University Hospital (Jeddah). Kuwait Medical Journal 2001; 33:127-30.

19. Pasha MB, Hashir MM, Pasha AK, Pasha MB, Raza $A A$, Fatima $M$. Frequency of esophageal varices in patients with upper gastrointestinal bleeding. Pak J Med Sci Sci 2011; 27:277-81.

20. Bhutta S, Jamil M, Aziz K. An etiological study of upper gastrointestinal bleeding. JRMC 2012; 16:31-3.

21. Nasir NU, Nadeem MA, Imran M, Hussain I. Oesophageal varices vs peptic ulcer: A study of 100 patients. Pak J Gastroeneterol 1998; 12:53-6.

22. Hossain E, Ahammed F, K Saha S, Foez SA, Rahim $M A$, et al. Screening of esophageal varices by noninvasive means in chronic liver disease. Euroasian J Hepatogastroenterol. 2018; 8(1):18-22.

23. Duah A, Nkrumah KN, Tachi K. Oesophageal varices in patients with liver cirrhosis attending a major tertiary hospital in Ghana. Pan African Med J. 2018; 31:230.

24. Haq I, Tripathi D. Recent advances in the management of variceal bleeding Gastroenter Rep 2017; 5(2): 11326.

25. Ofori-Asenso R, Agyeman AA. Hepatitis B in Ghana: A systematic review \& meta-analysis of prevalence studies (1995-2015). BMC Infect Dis. 2016; 16: 130.
26. Agyeman AA, Ofori-Asenso R, Mprah A, Ashiagbor G. Epidemiology of hepatitis $C$ virus in Ghana: $A$ systematic review and meta-analysis. BMC Infect Dis. 2016; 16: 391.

27. Iloh GU, Ikwudinma AO. Sero-epidemiology of Hepatitis B surface antigenaemia among adult Nigerians with clinical features of liver diseases attending a primary-care clinic in a resourceconstrained setting of eastern Nigeria. North Am J Med Sci. 2013; 5(4): 293-300.

28. Ayele AG, Solomon GS. Prevalence and risk factors of Hepatitis B and Hepatitis C Virus Infections among Patients with Chronic Liver Diseases in Public Hospitals in Addis Ababa, Ethiopia. ISRN Tropical Med. 2013; 2013: 563821.

29. Handady SO, Ahmed MA, Fadl AA, Alawad AAM. Precipitating factors of hepatic encephalopathy among Sudanese patients with Liver Cirrhosis. Medicine Journal. 2015; 2(4): 63-67.

30. Patricia LG, Maria da PZG, Carla CM, Ana TM, Carlos SG, Fausto ELP. Etiology of liver cirrhosis in Brazil: chronic alcoholism and hepatitis viruses in liver cirrhosis diagnosed in the state of Espfrito Santo. Clinics. 2013; 68(3): 291-295.

\begin{tabular}{|c|c|c|c|}
\hline \multicolumn{4}{|c|}{ AUTHORSHIP AND CONTRIBUTION DECLARATION } \\
\hline Sr. \# & Author(s) Full Name & Contribution to the paper & Author(s) Signature \\
\hline 1 & Talha Munir & $\begin{array}{l}\text { Data collection, Data analysis, } \\
\text { Paper writing. }\end{array}$ & \\
\hline 2 & M. Naeem Safdar & Data collection, Data analysis. & \\
\hline 3 & Salman Azhar & Data collection, Data analysis. & \\
\hline 4 & Rizwan Rasool Khan & Data collection & \\
\hline 5 & Samara Siddique & Paper writing. & enes \\
\hline 6 & Sahira Aaraj & Paper writing. & Salira \\
\hline 7 & Muhammad Ahsan & $\begin{array}{l}\text { Data entry, Data analysis, } \\
\text { Paper writing. }\end{array}$ & \\
\hline
\end{tabular}

